\title{
Research on the Discourse Power and Dominant Power of Ideological and Political Education in the Work of Mass Organizations in Universities
}

\author{
Xin-Jian ZHANG* \\ Tourism College \\ Shanghai Normal University \\ Shanghai, China
}

\begin{abstract}
The work of mass organizations is facing new opportunities and challenges under the new era background, which is an important part of the Party's work in universities. In the light of the 18th Party Central Committee's new strategy for reform and development of mass work, the university should proceed from the actual situation, adhe re to the discourse power and dominant power of ideological and political education, take the problem as the guidance, construct the discourse system which conforms to the characteristics of the mass organizations object, and choose the way suitable for the development of the mass organizations. Widening the breadth and coverage of ideological and political education, strengthening humane care and increasing the affinity and using public new media to provide carriers and platforms, in order to enhance the effectiveness of Ideological and political education, and promote the important role of the mass organizations work in educating people.
\end{abstract}

Keywords - the work of mass organizations; ideological and political education; discourse power and dominant power; path selection

\section{INTRODUCTION}

The work of mass organizations is an important part of the party's work in universities. The mass organizations are responsible for mobilizing the masses to work together for the party's central task. They are the growth cradle of youth and the masses, and also the party's ties to youth and the masses. From 2015, when the Central Committee convened a mass organizations work meeting for the first time, to the convening of the Nineteenth Congress, the important speeches of Chairman $\mathrm{Xi}$ at the two meetings gave instructions to the work and reflected the great attention of the Party Central Committee to the work. The spirit of the two conferences has pointed out that it is necessary to promote mass organizations to enhance "political, advanced, and mass nature," and put "political" in the first place particularly. The national ideological and political work conference for universities in 2016 also put forward the spirit of taking high moral values establishment and people cultivation as the fundamental task of education. The mass organizations work in universities must grasp the discourse power and dominant power of ideological and political education firmly, and enhance the political consciousness, which plays an important role in consolidating the mass foundation of the party's governance and promoting the healthy development of education.

\section{THEORETICAL CONCEPTS}

\section{A. Discourse Power and Dominant Power}

Discourse is a specific language activity in real life. It is not only a form of expression but also a way of thinking and action. Different industries or social life fields have different discourses. Discourse power does not refer to the popularity of language in a certain area, but refers to the influence and attractiveness generated by the elements, such as symbols, concepts, values, and ideology contained in discourse. The core of discourse power is the power relationship, which is embodied in the power of discourse issues, giving meaning to utterances, and formulating relevant rules ${ }^{[1]}$.

The so-called dominant power is a certain social ideology in the process of production and dissemination in the context of material production and living conditions. It plays a leading and leading role in the setting of topics, analysis of opinions, guidance of policies, and regulation of public opinions.

\section{B. Ideological and Political Education}

The main content of ideological and political education, the socialist ideology, focuses on reflecting the will and interests of our country's social subjects, demonstrating the exploration of social essences, goals, and operational mechanisms by the social subjects and the prediction of the direction of future social development ${ }^{[2]}$. Ideological and political education has become a force for promoting social development and human development. In practical work, ideological and political education is an important way to carry out "the production and distribution of ideas" ${ }^{3]}$. As long as we reflect the existence of ideologies of different countries, political parties, and institutions, ideological and political education will certainly be required to play a role. The ideological and political education of universities is to strengthen the ideological leadership of the party through ideological guidance and regulation, and to keep universities in all their work in socialism. The orientation of values ensures the correct direction of socialist construction with Chinese characteristics. 


\section{Discourse Power and Dominant Power of Ideological and Political Education in Universities}

Under the current social conditions, universities are faced with complex situations and backgrounds in their work. There is a huge amount of information disseminated, various cultures are interlaced and confrontation, various ideological trends are changing, and the discourse power and dominant power of ideological and political education are needed to control public opinion. The power to control the flow of consciousness is to use ideological and political education to guide people's ideological understanding and behavior, strengthen the norms, and rectify to a certain extent. It is not only the need to safeguard national ideological security, but also to guide people's development direction and social development. In the same direction, popular groups insist on the need of socialism with Chinese characteristics. Specifically speaking, the ideological and political education work must provide the party with a mass basis and guide the people in the direction of socialism in order to make value judgments. At the same time, it has the ability to lead and guide people's development and social development.

In actual work, insisting on the discourse power and dominant power of ideological and political education is essentially the use of Marxism as a guide for the work and ideological leadership. Under the current background of diversified social values and ideological and cultural diversity, there is only unwavering determination. To adhere to Marxism and use the socialist ideological and political theory with Chinese characteristics to educate the masses and guide the masses can effectively strengthen the guidance of ideology and ensure the correct orientation of the cause of socialism with Chinese characteristics.

\section{PRoBlems}

\section{A. The Mass Organizations Work}

The mass organizations work is an important content and front-line work area in the management of universities in China. The ideological and political education in group work is practical and diverse. The ideological and political education in group work is the trust and interaction between the subject of education and the subject of education with the content of ideological and political education as the common object and the discourse of ideological and political education as the medium through dialogue, mutual understanding and the time being reached. Obviously in this process, it is of great significance to realize the dominating purpose as a medium of ideological and political education. If ideological and political education cannot be integrated into the discourse system of the whole mission, it will not be able to play its due function.

\section{B. The Effectiveness of Ideological and Political Education is not Strong}

With the reform and development of the socialist market economy in China, great changes have taken place in the field of social life, people's values have also changed, and discourse capacity and innovation speed in group work have been unable to keep up with the pace of development of the times. It causes the effectiveness of ideological and political education to be weak. They are appeared in:

First, the working language lacks innovation and vitality. Many ideological and political education jobs are still traditional discourse and discourse thinking. They are unfamiliar with the language styles that are popular in group work. They are not good at combining new social language and ideological and political work languages into the working language. The traditional discourse is relatively standardized and cumbersome with respect to popular languages and web languages. It ignores the development of society and the independent intentions of the youth and the youth as well as the actual emotional needs. It lacks tolerance and patience in the process of educational exchanges. Therefore, when ideological education is conducted in traditional language, it is often indoctrinating, and the masses and youth will not have deep feelings. Second, the discourse of ideological and political education lacks the breadth of the field. In the group work of universities, we are often confined to the management of universities from the higher level to the lower level, administrative thinking and other discourse thinking make the content, meaning, and methods of ideological and political education all lack the breadth, and even some use executive orders. The language approach often fails to achieve the effectiveness of ideological and political education.

\section{The Pertinence of Ideological and Political Education is not Strong}

The development of society and the innovation of communication platforms have greatly changed the language ecology, discourse power pattern, and discourse patterns of the entire society. In the new era of media, people's expressions have become increasingly diverse, their speech rights have become more uncertain, and free speech has also shown rapid development. In addition, the trend of the times has led to the diversification of foreign languages, network languages, and popular people languages. These cultural changes and phenomena have subsequently had an important impact on people's production lifestyles and values. The current discourse and methods of ideological and political education do not focus on new development trends, they are not able to adapt to rapid development backgrounds and trends, there is no targeted language and work methods, and they cannot be expressed in the words, languages, or methods favored by the masses and youth. It cannot be resonated with them.

\section{The Dominance of Ideological and Political Education is not Strong}

The task group of colleges and universities is relatively a group with relatively high cultural level and theoretical qualities. Their general thinking is more active, they pay attention to individual thinking and viewpoints, they like to pay attention to new things and new situations, and keep pace with the times. Their needs are also diversified. In addition to the needs of material life, they also need spiritual needs. In terms of discourse, it is manifested as pluralism. It is eager to make a difference, desire and trend are close. They like to use network models and network language to communicate and work, pay attention to the publicity of individuality, like to pay attention 
to issues related to their own development, and to traditional ideology and politics. The low degree of recognition of the flat and traditional methods of education cannot fully and promptly accept the guidance of ideological and political education.

\section{PRINCIPLES}

\section{A. Changing Ideas}

Ideas determine concept, ideas determine discourse, grasp discourse power, and update discourse system need to changing the concept of ideological and political education. We must clearly define the methods and modes of group work. In the process of ideological and political education, the educators and the educated have the subjectivity. The interaction between them is based on the relationship of equal relationships. It cannot be entirely from above. The next model is to establish the discourse mechanism of equal dialogue between subjects, and ideological and political education can be effective.

\section{B. Based on the Masses}

The establishment and development of a socialist market economic system has enhanced the autonomy of the subject and formed a social competition mechanism. We must not only oppose individualism while conducting ideological and political education. At the same time, we must proceed from reality and pay attention to human reality and concreteness. The interests of the society, the future and the society, help people establish the overall and long-term concepts and form the correct ideals and beliefs. In particular, the masses and young people are energetic and passionate. They have their own characteristics of discourses, desire for personal interactions and inner relations, and ideological and political education must be based on the masses, grasp these personalities and characteristics, and conduct education in a true and accurate manner, to evoke work object's recognition and resonance.

\section{Development through Practice}

The rapid development of society as a whole, and especially the transformation of new media and modes of communication, has rapidly changed the linguistic ecology, discourse power patterns, and discourse patterns of society. People's role orientation has become increasingly rational, with increased attention to and participation in various social phenomena and events, as well as clear independent opinions and speculative processes. The development of the language ecological environment requires that ideological and political education should be based on the development of the language practice of the group objects, understand their discourse systems and changes, and on the other hand require that the discourse system of the ideological and political education itself is very important to adapt and update.

\section{Path Selection}

\section{A. Using Public New Media to Provide Carriers and Platforms}

The work discourse is spread through the media, and the establishment of the discourse power of ideological and political education must be studied and utilized by various new media, and its function can be achieved through diversification and rapid dissemination. In today's society, the development of science and technology has produced a large number of new media, and various media platforms such as QQ, Weibo, and Wechat have been rapidly updated and developed. Moreover, the continuous promotion of information and networking is that these new media and platforms have become the hubs of different thoughts and opinions, and they can also be said to be the battlefield for discourse power. We must make full use of these new media with strong participation and use the interactive nature of this new medium to achieve the guiding function of ideological and political education.

\section{B. Strengthen the humane care, increase appeal and affinity}

The discourse power is a method. The dominant power is a purpose, but the discourse itself is not a closed structure. It is placed in a complex and changing real social life. In the actual work, we face the real context and close to reality. Your words can be effective in order to achieve your goals. In the group work, all the individuals are living, they are specific and individual, and they should pay attention to every work event, listen to the voice of the masses, understand their language and experience for ideological and political educators. In practical problems and difficulties encountered by the masses, they must use effective and effective discourse and methods to carry out their work. If necessary, they must strengthen discourse conversion and meet the requirements of the times, practical requirements, and mass demands, so as to enhance the appeal and affinity of discourse. Only in this way can we promote the effective development of ideological and political education.

\section{Expanding Coverage to Establish a Socialized Pattern}

The group work in universities is not a single campus work. There are many social changes in carrying out ideological and political education, and the accepted context and environment are also diverse and rapid. In carrying out group work, the most basic thing for ideological and political education is participation, which involves the participation of ideological and political education in the social space. It is an important foundation for ideological and political education to explain social phenomena and influence people. Therefore, it is necessary to expand the breadth and coverage of ideological and political education and to face all the objects of the group work and their activities. In addition, this education should be socialized and comprehensive. It must establish a socialized pattern, including a new type of social space, such as network virtual space, to ensure that the ideological and political education can be held in place.

\section{SUMMARY}

At present, under the conditions of reform and opening up, in the process of rapid development of social information, the 
situation in the ideological and political realm is relatively complicated. Various ideological and cultural exchanges, interactions, and confrontations are increasingly prominent. We must adhere to certain principles in our regrouping work. Resist all kinds of challenges and firmly grasp the discourse power and dominant power. The construction of ideological and political education discourse power in the mass organizations work, the construction of a new discourse system, and the demonstration of the appeal and explanatory power of the ideological and political education discourse are determined by many factors.

\section{REFERENCES}

[1] Jin-Long CHEN. On the construction of the discourse power of socialism with Chinese characteristics, Ideological and theoretical education, Shanghai, 2015(03), pp.08-12.

[2] Yong-Ting ZHENG, Qun CAO. Insisting on the right to speak and dominate in the subject of Ideological and Political Education, Ideological and theoretical education, Shanghai, 2015(03), pp.45-48.

[3] Selections (Anthologies) of Marx and Engels, vol. 1. Beijing: People's Publishing House 1995, p. 99 